\title{
Peran Human Capital, Corporate Value dan Good Corporate Governance melalui Kinerja Karyawan terhadap Kinerja Perusahaan di PTPN VII Lampung
}

The Role of Human Capital, Corporate Values and Good Corporate Governance through the Employee Performance in the Company Performance at PTPN VII in Lampung

\author{
Husen Sutisna*1, Aida Vitayala S. Hubeis $^{2}$ dan Muhammad Syamsun ${ }^{3}$ \\ ${ }^{1}$ Program Magister Ilmu Manajemen, Sekolah Pascasarjana Institut Pertanian Bogor \\ ${ }^{2}$ Departemen Komunikasi dan Pengembangan Masyarakat, Fakultas Ekologi Manusia, Institut Pertanian Bogor \\ ${ }^{3}$ Departemen Manajemen, Fakultas Ekonomi dan Manajemen, Institut Pertanian Bogor \\ Jl. Kamper, Kampus IPB Darmaga, Bogor 16680
}

\begin{abstract}
ABSTRAK
Perubahan yang terjadi dalam lingkungan bisnis menyebabkan berbagai perusahaan terus berusaha memperbaiki strategi bisnisnya, bertujuan agar bisa bertahan dan mempunyai keunggulan bersaing. Puncak perubahan tersebut dengan dimulainya era bisnis pada era informasi dan era pengetahuan. Pada era ini strategi bisnis yang dipandang cocok diantaranya penerapan sistem pengembangan SDM berbasiskan human capital dan pengelolaan perusahaan berbasiskan nilai-nilai (corporate value) dan good corporate governance (GCG). Perseroan Terbatas Perkebunan Nusantara (PTPN) VII sebagai perusahaan BUMN bidang agribisnis berupaya menerapkan sitem tersebut. Penelitian ini bertujuan mengkaji bagaimana hubungan antara human capital, corporate value dan good corporate governance (GCG),serta kaitannya terhadap kinerja karyawan dan kinerja perusahaan. Populasi penelitian ini adalah karyawan kantor pusat PTPNVII sebanyak 400 orang. Dimana jumlah contoh yang ditetapkan 120 responden. Teknik penarikan contoh yang digunakan adalah non probability sampling dengan teknik quota sampling. Metode pengolahan dan analisis data menggunakan Analisis struktural equation modelingpartial least squares (SEM-PLS), pengolahan data mengunakan sofware smartPLS. Hasil penelitian ini menunjukan bahwa implementasi human capital yangdilakukan oleh perusahaan berperan positif terhadap peningkatan kenerja karyawan. Implementasi dan internalisasi corporate value terhadap karyawan berperan posititif terhadap peningkatan kinerja karyawan. Peningkatan kinerja karyawan berperan positif meningkatkan kinerja perusahaan. Implementasi prinsip-prinsip GCG dapat meningkatkan kinerja perusahaan, tetapi tidak dapat memberikan pengaruh dalam peningkatan kinerja karyawan.
\end{abstract}

Kata kunci: human capital, corporate value, good corporate governance, kinerja karyawan, kinerja perusahaan

\section{ABSTRACT}

Changes in business environment lead various companies to continue to strive to improve their business strategies in order to survive and have a competitive advantage. The peak changes occurred with the coming of business era in the era of information and science. In this era, business strategies that are considered suitable, among others, the application of human resource development system based on human capital and company management based on corporate values and good corporate governance (GCG). PTPN VII as state-owned enterprise in agribusiness has tried to implement the system. This study aimed to examine the relationship between human capital, corporate values and GCG and their relation to the performances of the employees and the company. The population of this research as many as 400 people consisted of the employees of PTPN VII head office, but the number of the samples set was 120 respondents. The sampling technique used was non-probability sampling with quota sampling technique. The methods of processing and analyzing the data was structural equation modeling analysis-

\footnotetext{
*) Korespondensi:

Jl. Sholeh Iskandar, Bogor Raya Permai Blok FF1 No. 01 Kota Bogor; e-mail: husensukses@yahoo.co.id
} 
partial least squares (SEM-PLS), and the data processing used software smartPLS. The results indicated that the implementation of human capital by the company contributed positively to the increase of the employee performance. The implementation and internalization of corporate values to the employees positively contributed to the improvement of the employee performance. The increased employee performance played a positive role in improving the company performance. The implementation of corporate governance principles could improve the performance of the company, but did not play a great role in improving employee performance.

Key word: company performance, corporate values, employee performance, good corporate governance, human capital

\section{PENDAHULUAN}

Perubahan yang disebabkan oleh globalisasi industri, kemajuan informasi, perkembangan teknologi dan persaingan yang ketat, menyebabkan berbagai perusahaan mengubah strategi dalam menjalankan bisnisnya, diantaranya perubahan pradigma bisnis dari resources based business menjadi knowledge based business, dari dominan investasi pisik (physical assets) menjadi dominan investasimodal intelektual (intelectual assets). Menurut Barrett (2010) ada empat periode perubahan yang dilalui manusia dalam menjalankan aktifitas bisnisnya, yaitu era agraris (agricultural age), era industri (industrial age), era informasi (information age) dan era kesadaran (consciousness age).

Era Agraris, manusia bertumpu pada pertanian, besarnya keuntungan tergantung pada jumlah dan kekuatan SDM yang dimiliki serta sumber daya alam yang dikuasai, dicirikan dengan penguasaan lahan pertanian atau jumlah ternak yang dimiliki (Purwanto 2010). Era Industri, yang menentukan kesuksesan sebuah bisnis adalah mutu produk yang dihasilkan, produktifitas, efisiensi dan marketing masal, dicirikan dengan kepemilikan atas mesin atau teknologi produksi dan pabrik (Purwanto 2010).

Era Informasi sering disebut juga sebagai era pengetahuan (era knowledge). Fokus perhatian pada era pengetahuan adalah sumber daya manusia (SDM) dan penguasaan teknologi informasi (TI), peran TI untuk mengolah data menjadi informasi dan peran SDM mengelola atau memberi arti informasi menjadi pengetahuan, kemudian pengetahuan tersebut ditransformasikan menjadi produk atau pelayanan (Purwanto 2010). SDM dijadikan intagible assets, artinya SDM sebagai aset penting bagi perusahaan. Bentuk aset tersebut berupa modal intelektual (Intellectual Capital). Modal intelektual menggambarkan kemampuan karyawan menggunakan pikirannya untuk meghasilkan ide-ide kreatif dan inovatif.
Ciri utama pada era ini penguasaan informasi, pengetahuan (knowledge), pembelajaran (learning), pemberdayaan (empowerment), pertumbuhan individu (personal growth), dan kepuasan pelanggan.

Eraconsciousness dimulai sejak Tahun 2000an. Pada era ini perusahaan tidak bisa lagi hanya mengandalkan kekuatan intelektual SDM, tetapi mulai menyadari pentingnya modal budaya (Cultural Capital) dalam sebuah perusahaan. Ciri utamanya pembentukan dan internalisasi corporate value, etika, kolaborasi (collaboration) dan corporate social responsibility (CSR).

Perseroan Terbatas Perkebunan Nusantara (PTPN) VII sebagai perusahaan Badan Usaha Milik Negara (BUMN) di bidang Agribisnis telah menerapkan sistem pengembagan SDM berbasiskan human capital dan operasional perusahaan berbasiskan corporate value dan good corporate governance (GCG). Perusahaan ini bergerak dalam bidang perkebunan komoditi kelapa sawit, karet, tebu dan teh. PTPN VII mempunyai prinsip bahwa SDM adalah aset potensial yang harus dikelola dan dikembangkan. Optimalisasi pengelolaan SDM tersebut berbasiskan Human Capital Management System, salah satu hasilnya PTPN VII mendapatkan penghargaan Indonesian Human Capital Study pada Tahun 2011, diberikan oleh Dunamis Human Capital dan Majalah Business Review. Realisasi anggaran pelatihan dan pengembangan SDM cukup besar, pada Tahun 2009 Rp5,79 miliar, Tahun 2010 Rp4,99 miliar, Tahun 2011 Rp10,07 miliar, Tahun 2012 Rp9,61 miliar dan Tahun 2013 Rp4,26 miliar.

Perusahaan juga telah membangun dan berupaya menginternalisasi corporate value kepada seluruh karyawan, dikenal dengan iconThe Spirit of Change ProMOSI. Kata ProMOSI merupakan singkatan dari lima nilai dasar perusahaan, yaitu: produktivitas, mutu, organisasi, servis dan inovasi.

PTPN VII memiliki komitmen yang tinggi untuk meningkatkan GCG dengan sebaik-baiknya melalui implementasi seluruh prinsip-prinsip 
GCG yang terdiri atas transparansi, akuntabilitas, resposibilitas, independensi dan kewajaran. Perusahaan berkeyakinan bahwa penerapan GCG akan mendorong organisasi untuk menghasilkan kinerja unggul dan memiliki nilai tambah ekonomi pemegang saham dan para stakeholder, termasuk pengurus perusahaan dan karyawan. Hal ini terbukti dengan perolehan skor GCG yang terus menunjukan peningkatan. Tahun 2004 skor GCG 69,66, Tahun 2005 skor GCG 79,51, Tahun 2007 skor GCG 80,18, Tahun 2010 skor GCG 82,48, Tahun 2012 skor GCG 80,18 dan Tahun 2013 skor GCG 83,17. Implementasi GCG di PTPN VII termasuk kategori baik.

Kinerja perusahaan Tahun 2013 dibandingkan dengan tahun sebelumnya mengalami peningkatan. Hal ini terlihat dari realisasi laba bersih Tahun 2013 mencapai Rp78,6 milyar, meningkat $44,7 \%$ dibandingkan tahun 2012 , nilai penjualan bersih mencapai Rp4,62 milyar, meningkat 5,9\% dibandingkan tahun 2012.

Tujuan penelitian ini: (1) Menganalisis peran human capital terhadap kinerja karyawan. (2) Menganalisis peran corvorate value terhadap kinerja karyawan (3) Menganalisis peran GCG terhadap kinerja karyawan. (4) Menganalisis peran kinerja karyawan terhadap kinerja perusahaan. (5) Menganalisis peran implementasi prinsip GCG terhadap kinerja perusahaan.

\section{METODOLOGI}

Human capital memiliki lima komponen yaitu individual capability, individual motivation, leadership, the organizational climate dan work group effectiveness (Mayo 2000). Human capital terdiri dari innovation dan creation, learning dan education, and experience dan expertise (Sharabati et al. 2010). Menurut Ployhart dan Moliterno (2011) konsep human capital merupakan sumberdaya yang muncul dari knowledge, skills, abilities, and other characteristics (KSAOs) sebagai individu karyawan. Wrightat al. (2013) menjelaskan human capital terdiri dari dimensi dan karakteristik sebagai berikut; ability, personality, skill, knowledge, affect dan behavior.

Corporate value adalah nilai-nilai yang dipegang teguh dan diyakini oleh seluruh karyawan dan kemudian teraplikasi dalam perilaku kolektif dan menjadi tulang punggung keberlangsungan perusahaan (Atmadja 2009). PTPN VII telah menetapkan lima nilai dasar perusahaan (corporate value), yang terdiri dari produktivitas, mutu, organisasi, servis, dan inovasi. Tata nilai inimerupakan landasan dalam membangun budaya perusahaan. Nilai-nilai tersebut diharapkan dapat menjiwai setiap sikap dan perilaku semua karyawan dalam aktivitas sehari-hari, baik sebagai karyawan maupun sebagai pribadi (PTPN VII 2013).

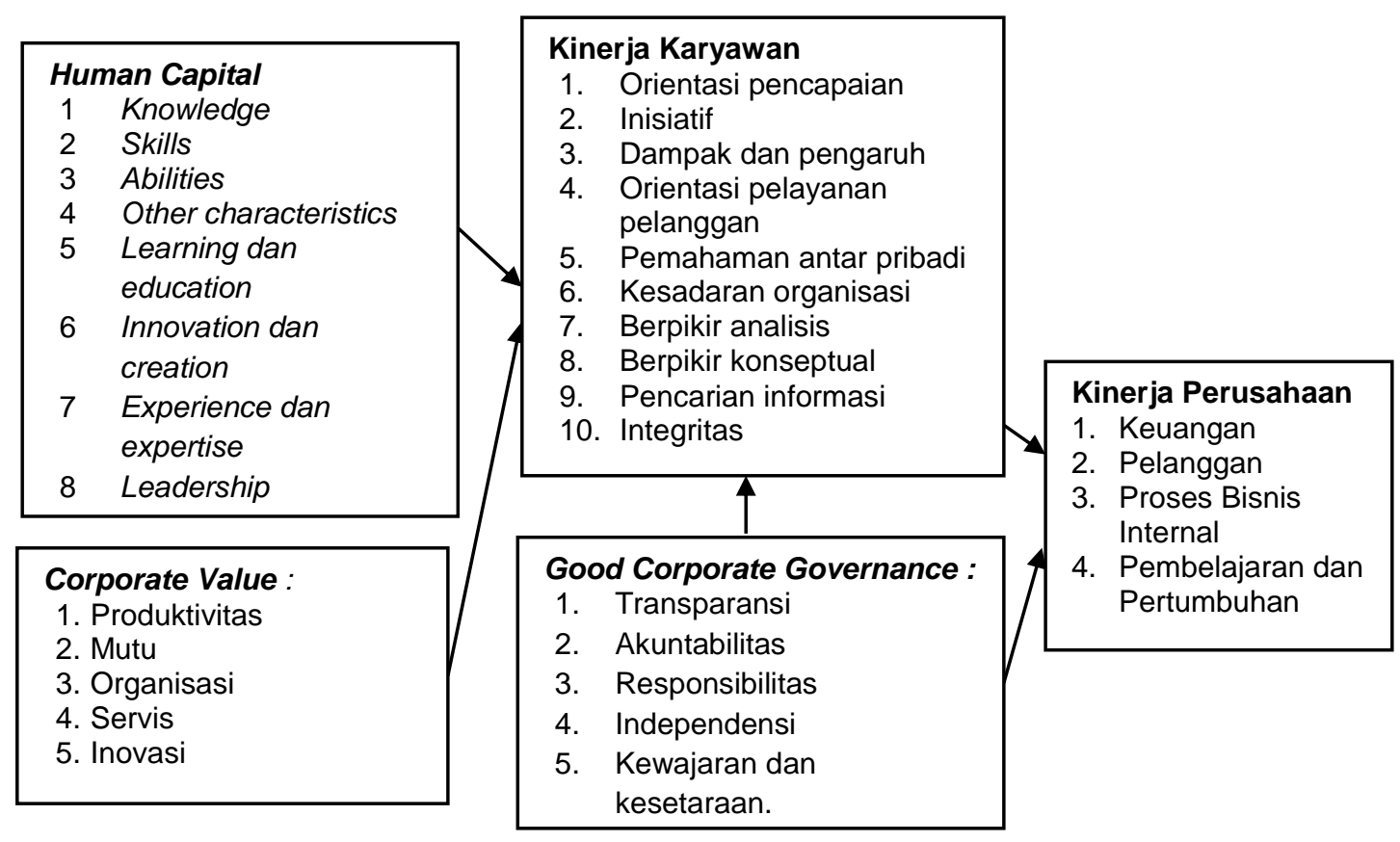

Gambar 1. Kerangka berpikir penelitian 
Menurut Mangkunegara (2005), kinerja adalah hasil kerja secara kuantitas dan kualitas yang dicapai oleh seorang karyawan dalam melaksanakan tugasnya sesuai dengan tanggung jawab yang diberikan kepadanya. Penilaian kinerja berbasis kompetensi adalah cara organisasi mengevaluasi karyawan berdasarkan apa yang telah dilakukan dan bagaimana melakukannya, sejak akhir periode penilaian kinerja sebelumnya (Kessler, 2011). Standar penilaian kinerja berbasis kompetensi yang paling banyak digunakan diantaranya orientasi pencapaian, inisiatif, dampak dan pengaruh, orientasi pelayanan pelanggan, pemahaman antar pribadi, kesadaran organisasi, berpikir analisis, berpikir konseptual, pencarian informasi dan integritas (Kessler, 2011).

Menurut Kemen BUMN (2002) GCG adalah suatu proses atau struktur yang digunakan oleh BUMN untuk meningkatkan keberhasilan usaha dan akuntabilitas perusahaan guna mewujudkan nilai pemegang saham dalam jangka panjang dan tetap memperhatikan kepentingan stakeholder lainnya, berlandaskan peraturan perundangundangan dan nilai-nilai etika. GCG memiliki lima prinsip, yaitu transparansi, akuntabilitas, responsibilitas, independensi serta kewajaran dan kesetaraan (KNKG, 2006).

Balanced scorecard (BSC) digunakan untuk mengukur kinerja perusahaan secara berimbang antara keuangan dan non keuangan, jangka pendek dan jangka panjang, internal dan eksternal. Pengukuran kinerja perusahaan dalam BSC dilakukan secara menyeluruh dari semua aspek bisnis, yang terdiri dari empat perspektif, yaitu perspektif keuangan, pelanggan, proses bisnis dalam perusahaan serta proses pembelajaran dan pertumbuhan (Kaplan dan Norton 1996).

Berdasarkan kajian berbagai teori dan permasalahan di perusahaan, dapat dikemukakan hipotesis penelitian sebagai berikut; $\mathrm{H}_{1}$ : human capital berpengaruh nyata terhadap kinerja karyawan. $\mathrm{H}_{2}$ : corporate value berpengaruh nyata terhadap kinerja karyawan. $\mathrm{H}_{3}$ : Kinerja karyawan berpengaruh nyata terhadap implementasi prinsip-prinsip GCG. $\mathrm{H}_{4}$ : Kinerja karyawan berpengaruh nyata terhadap kinerja perusahaan. $\mathrm{H}_{5}$ : GCG berpengaruh nyata terhadap kinerja perusahaan.

Penelitian ini dilaksanakan di kantor pusat PTPN VII yang berlokasi di Propinsi Lampung. Kegiatan penelitian dilakukan pada bulan MeiJuni 2014. Pengumpulan data dilakukan dengan penyebaran kuesioner kepada responden dan wawancara langsung, serta pengambilan data bersifat persepsi. Populasi penelitian adalah karyawan kantor pusat PTPN VII berjumlah 400 orang. Jumlah contoh yang ditetapkan 120 responden. Kuesioner yang kembali dan dapat diolah 88 kuesioner. Metode pengolahan dan analisis data pada penelitian ini menggunakan analisis structural equation modeling-partial least squares (SEM-PLS) dan bantuan sofware smartPLS.

\section{HASIL DAN PEMBAHASAN}

Evaluasi output model penelitian menggunakan program SmartPLS dilakukan dua tahap, evaluasi model pengukuran (outer model) dan evaluasi model struktural (inner model). Evaluasi outer model mengukur peubah indikator dapat mencerminkan atau merefleksikan peubah latent atau konstruk. Evaluai Inner model meliputi nilai nyata tiap koefesien jalur yang menyatakan apakah ada nyata atau tidaknya pengaruh antar konstruk (variabel laten) yang dihipotesiskan. Output model penelitian disajikan pada Gambar 2.

Tabel 1. Ringkasan hasil evaluasi model outer

\begin{tabular}{|c|c|c|}
\hline No & Kriteria & Nilai Hasil Penelitian vs Standar \\
\hline 1 & $\begin{array}{l}\text { Indikator } \\
\text { validitas }\end{array}$ & $\begin{array}{l}\text { Indikator dikatakan valid, memiliki } \mathrm{t} \text { statistik }>2,0 \text { Nilai loading faktor }>5 \text {. Semua } \\
\text { indikator mempunyai validitas nyata. }\end{array}$ \\
\hline 2 & $\begin{array}{l}\text { Reliabilitas } \\
\text { konstrak }\end{array}$ & $\begin{array}{l}\text { Melihat output cronbach's alpha. Kriteria dikatakan reliable adalah nilai composite } \\
\text { reliabilitycronbach's alpha lebih dari } 0,7 \text {. Hasil : cronbach's alpha CV }(0,7851\} \text {, GCG } \\
(0,8691) \text { dan HC }(0,7307) \text {, semuanya diatas } 0,7 \text {. }\end{array}$ \\
\hline 3 & $A V E$ & $\begin{array}{l}\text { Konstruk memiliki convergent validity yang baik adalah apabila nilai akar AVE } \\
\text { lebih dari } 0,5 \text {. Hasil : CV }(0,5580) \text {, GCG }(0,6646) \text { dan HC }(0,5815) \text {. }\end{array}$ \\
\hline 4 & $\begin{array}{l}\text { diskriminant } \\
\text { validity }\end{array}$ & $\begin{array}{l}\text { Setiap indikator berkorelasi lebih tinggi dengan konstruk masing-masing, } \\
\text { dibandingkan dengan konstruk lainnya, artinya hubungan indikator dengan } \\
\text { konstruk memiliki discriminant validity yang baik. }\end{array}$ \\
\hline
\end{tabular}




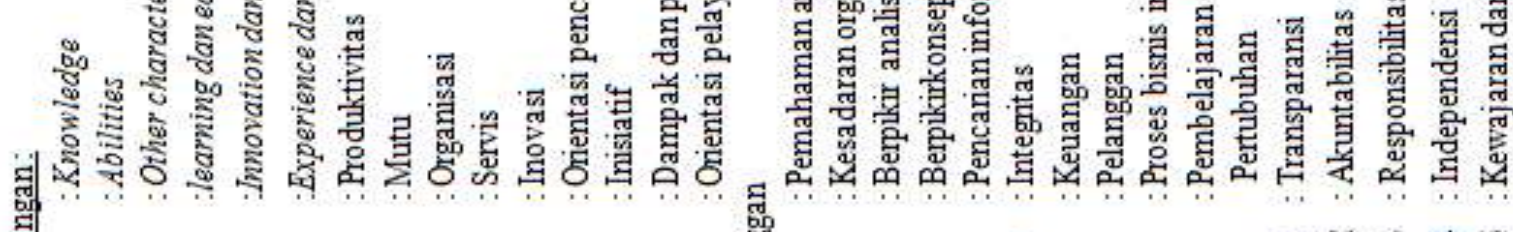

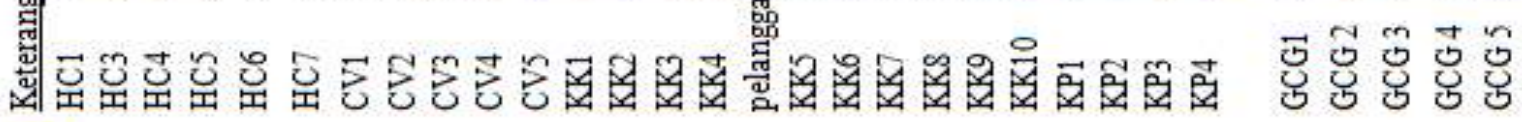

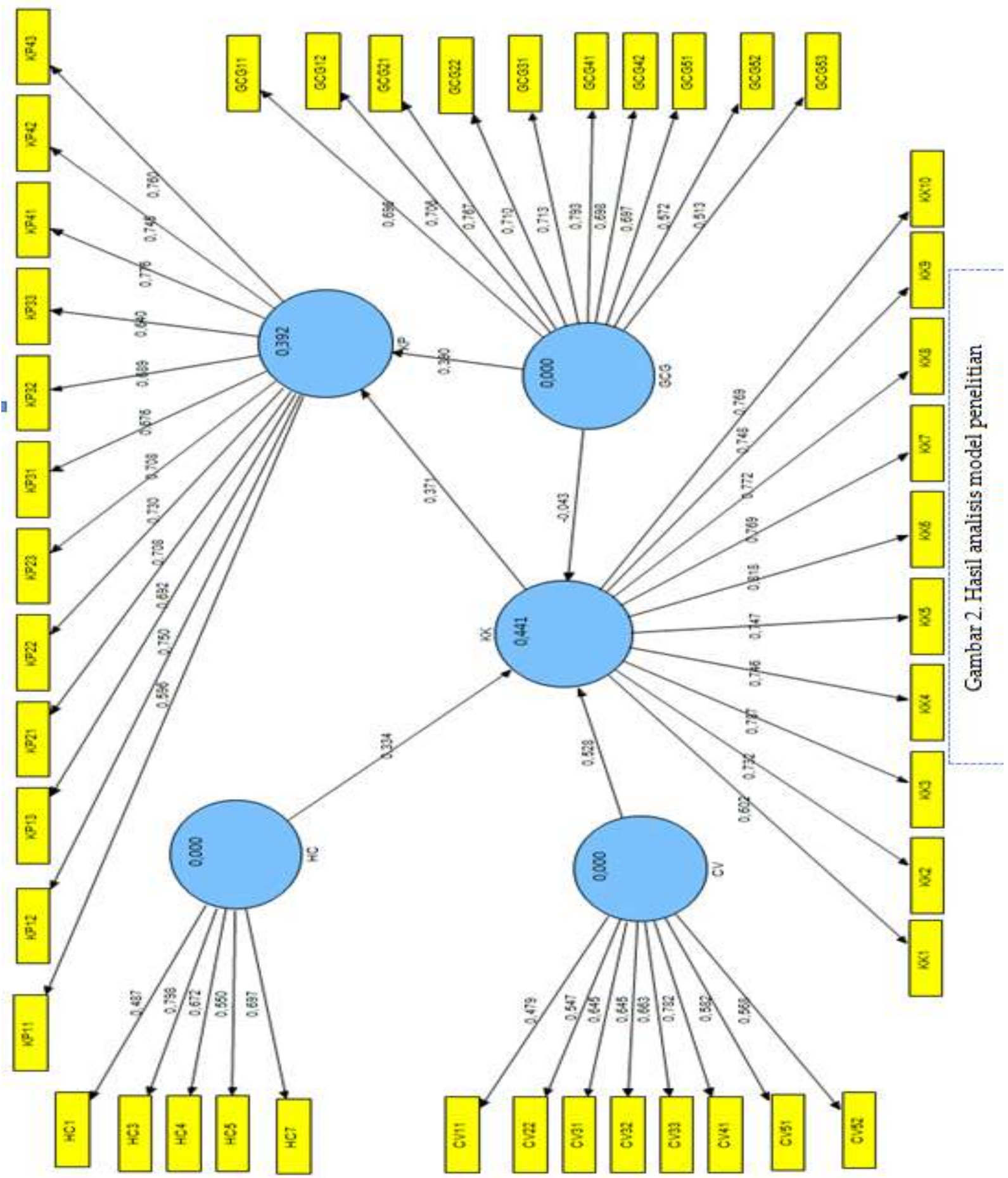


Tabel 3. Nilai hasil penelitian dan kriteria standar evaluasi inner model

\begin{tabular}{|c|c|c|}
\hline No & Kriteria & Nilai Hasil Penelitian vs Standar \\
\hline 1 & $\begin{array}{l}R^{2} \text { dari peubah } \\
\text { laten endogenous }\end{array}$ & $\begin{array}{l}\text { Standar kriteria batasan nilai } R^{2} \text { ini dalam tiga klasifikasi, yaitu nilai } R^{2} \\
0,67,0,33 \text { dan } 0,19 \text { sebagai subtansial, moderat dan lemah (Chin 1998). } \\
\text { Hasil : KK=0,4406, KP=0,3923 }\end{array}$ \\
\hline 2 & Estimasi model path & $\begin{array}{l}\text { Hasil bootstrap koefesien path didapatkan pengaruh yang sangat nyata } \\
\text { antara } \mathrm{CV} \text { terhadap KK, HC terhadap KK ,GCG terhadap KP dan KK } \\
\text { terhadap KP dengan nilai tstatistik lebih dari } 2,0 \text {. }\end{array}$ \\
\hline 3 & $\begin{array}{l}Q^{2} \text { predictive } \\
\text { relevance }\end{array}$ & $\begin{array}{l}\text { Berfungsi untuk memvalidasi kemampuan prediksi model. Jika nila } \\
Q^{2} \text { lebih besar dari nol menunjukan peubah laten eksogen baik (sesuai) } \\
\text { sebagai peubah penjelas yang mampu memprediksi peubah endogennya. } \\
\text { Hasil : bahwa nilai semua kontrak laten memiliki predivtive relevance yang } \\
\text { baik, nilai } Q^{2} \text { lebih dari nol (0). }\end{array}$ \\
\hline
\end{tabular}

Tabel 4. Hasil uji hipotesis

\begin{tabular}{clcccc}
\hline Hipotesis & Konstruk & $\begin{array}{c}\text { Orginal } \\
\text { Contoh }\end{array}$ & $\begin{array}{c}\text { Simpangan } \\
\text { Baku }\end{array}$ & $\begin{array}{c}\text { t Statistik } \\
\text { (IO/STERRI })\end{array}$ & Keterangan \\
\hline H1 & HC -> KK & 0,3339 & 0,0998 & 3,3459 & Terima \\
H2 & CV -> KK & 0,5283 & 0,1203 & 4,3922 & Terima \\
H3 & GCG -> KK & $-0,0428$ & 0,1030 & 0,4157 & Tolak \\
H4 & KK -> KP & 0,3706 & 0,0869 & 4,2660 & Terima \\
H5 & GCG -> KP & 0,3743 & 0,0853 & 4,3900 & Terima \\
\hline
\end{tabular}

\section{Peran Human Capital terhadap Kinerja Karyawan}

Penerimaan $\mathrm{H}_{1}$ mengindikasikan bahwa human capital mempunyai pengaruh nyata terhadap kinerja karyawan. Hal ini menguatkan hasil penelitian sebelumnya yang dilakukan oleh Anis (2013), Astuti (2011), Sharabati et al. (2010) dan Wuet al. (2012). Awan dan Sarfraz (2013) juga menyampaikan hasil penelitiannya bahwa perusahaan yang berupaya terus meningkatkan skills dan abilities yang merupakan bagian dari investasi human capital dapat membantu dalam meningkatan kinerja yang lebih baik.

Temuan hasil penelitian menunjukan bahwa semakin baik implementasi human capital yang dilakukan oleh perusahaan, maka kinerja karyawan akan semakin meningkat. Faktor human capital yang menjadi prioritas pertama adalah peningkatan Abilities berupa kemampuan dan semangat kerja karyawan. Faktor human capital ketiga yang dapat meningkatkan kinerja karyawan adalah pemberian kesempatan untuk melakukan kreatifitas dalam bekerja. Faktor human capital yang terakhir yang dapat meningkatkan kinerja karyawan adalah memberikan kesempatan kepada karyawan untuk menambah pemahaman dan pengetahuannya, terutama yang berkaitan dengan apa yang dikerjakan. Hal ini berkaitan dengan learning proses bisa dilakukan dengan pendidikan dan pelatihan (diklat). Pendidikan bisa dilakukan dengan mendorong karyawan untuk belajar secara formal, misal pemberian kesempatan untuk kuliah atau melanjutkan jenjang pendidikannya, akan lebih baik jika perusahaan memfasilitasi dalam hal pembiayaan. Pelatihan bisa dilakukan berupa in hous training, coaching, conselor dan mentoring.

\section{Peran Corporate Value terhadap Kinerja Karyawan}

Penerimaan $\mathrm{H}_{2}$ mengindikasikan bah-wa corporate value mempunyai pengaruh nyata terhadap kinerja karyawan. Hal ini menguatkan hasil penelitian sebelumnya yang dilakukan oleh Suryadi dan Rosyidi (2013) serta Uddin at al. (2013). Yang menjadi fokus kajian corporate value dalam penelitian ini adalah terkait dengan nilainilai perusahaan yang selama ini diterapkan oleh perusahaan diantaranya produktivitas, mutu, organisasi, servis dan inovasi.

Temuan hasil penelitian menunjukan bahwa semakin baik internalisasi corporate value yang dilakukan oleh karyawan maka kinerja karyawan akan semakin meningkat atau dengan kata lain karyawan yang mampu menginternalisasi dan mengaplikasikan nilai-nilai perusahaan, maka kinerja karyawan tersebut akan semakin baik. Nilai-nilai (values) merupakan salah satu unsur pembentuk budaya perusahaan yang penting, dipegang teguh dan diyakini oleh semua karyawan kemudian teraplikasi dalam perilakuku kolektif akan menjadi tulang punggung keberhasilan perusahaan (Atmadja, 2009). Corporate value yang selama ini diyakini dan dipegang 
teguh oleh karyawan PTPN VII diantaranya produktivitas, mutu, organisasi, servis dan inovasi.

Faktor Pelayanan atau servis memberikan peran terbesar dalam membangun corporate value, diantaranya pelayanan terbaik untuk semua stakeholder seperti kepada atasan, rekan kerja, bawahan dan konsumen, serta pentingnya pengetahuan karyawan kepada siapa harus mempertanggungjawabkan wewenangnya. Faktor organisasi memberikan peran terbesar kedua dalam membangun corpoorate value, diantaranya pentingnya hubungan ketenagakerjaan yang baik dan pemahaman karyawan terhadap apa yang menjadi tugasnya. Artinya semakin baik hubungan ketenagakerjaan dan pemahaman karyawan terhadap tugasnya akan memberikan peran posititif dalam membangun corporate value yang pada akhirnya akan memberikan peran positif terhadap kinerja karyawan.

Faktor Inovasi memberikan peran terbesar ketiga dalam membangun corporate value, diantaranya pentingnya karyawan dan perusahaan melakukan inovasi atau terobosan-terobosan baru baik berupa gagasan, sistem maupun produk, agar bisa mengikuti perubahan yang terjadi. Artinya semakin baik proses inovasi atau terobosan-terobosan baru akan memberikan peran posititif dalam membangun corporate value, yang pada akhirnya memberikan peran positif terhadap kinerja karyawan. Indikator berikutnya membangun corporate value dengan mutu dan produktivitas. Mutu terkait dengan mutu pengiriman barang kepada konsumen yang tepat waktu dan produktifitas terkait dengan pentingnya pengelolaan sumberdaya yang dimiliki dengan baik.

\section{Peran GCG terhadap Kinerja Karyawan}

Penolakan $\mathrm{H}_{3}$ mengindikasikan GCG tidak mempunyai pengaruh nyata terhadap kinerja karyawan. Penekanan pengkajian GCG dalam penelitian ini di refleksikan prinsip-prinsip GCG yang terdiri dari transparansi, akuntabilitas, responsibilitas, independensi, kewajaran dan kesetaraan. Hal ini terjadi karena penerapan GCG merupakan suatu sistem atau seperangkat peraturan yang mengatur hubungan antara organ perusahan (level organisasi), diantaranya pemegang saham, dewan komisaris dan dewan direksi. Tujuannya agar bisa memberi nilai tambah bagi perseroan, bisa menentukan arah pengembangan dan meningkatkan kinerja perseroan, serta berjalannya fungsi-fungsi pengelolaan perusahaan secara efektif dan efisien.

\section{Peran Kinerja Karyawan terhadap Kinerja Perusahaan}

Penerimaan $\mathrm{H}_{4}$ mengindikasikan bahwa kinerja karyawan mempunyai pengaruh nyata terhadap kinerja perusahaan. Kinerja karyawan dibangun dari konstruk eksogen yang nyata diantaranya, human capital dan corporate value. Artinya kinerja perusahaan bisa ditingkatkan dengan perbaikan kinerja karyawanmelalui pengembangan SDM berbasiskan human capital yang meliputi peningkatan knowledge, skill, other characteristics, learning dan education, innovation dan creation dan experiencel expertise. Selain ini itu kinerja perusahaan bisa dilakukan dengan melakukan internalisasi corporate value yang terdiri produktivitas, mutu, organisasi, servis dan inovasi.

\section{Peran GCG terhadap Kinerja Perusahaan}

Penerimaan $\mathrm{H}_{5}$ mengindikasikan implementasi prinsip-prinsip GCG mempunyai pengaruh nyata terhadap kinerja perusahaan. Hal ini menguatkan hasil penelitian sebelumnya yang dilakukan Anis (2013). Pengkajian GCG dalam

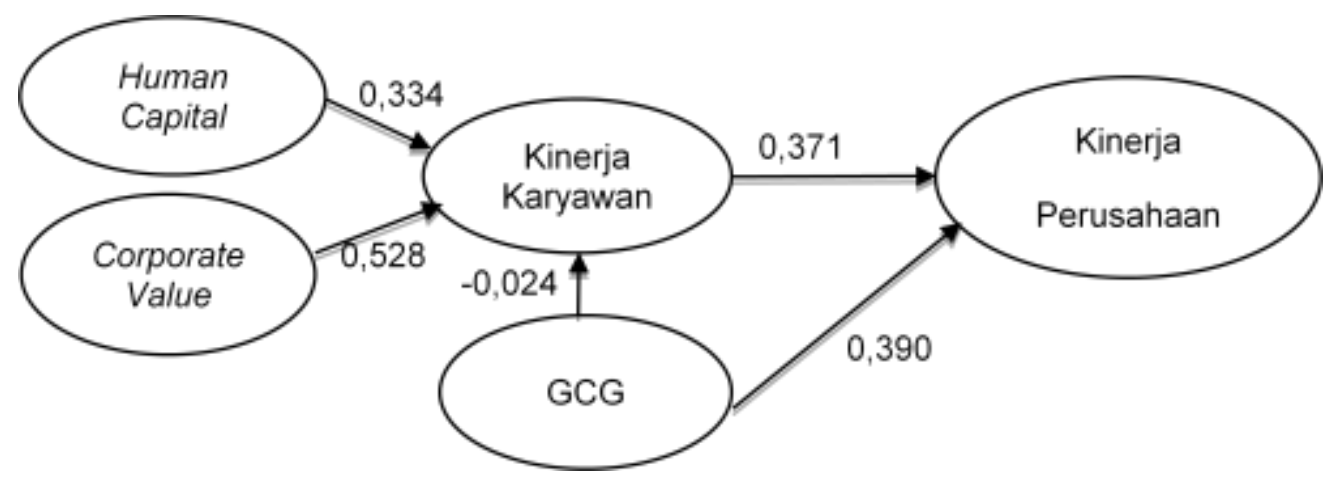

Gambar 3. Hubungan antar konstruk penelitian 
penelitian ini terkait dengan imlementasi prinsipprinsip GCG seperti transparansi, akuntabilitas, responsibilitas, independensi, kewajaran dan kesetaraan. Hasilnya menunjukan untuk meningkatkan GCG perlu dilakukan pengelolaan perusahaan secara independen (indepedensi), perusahaan mampu mempertanggungjawabkan kinerjanya secara transparan (akuntabilitas) dan perusahaan mampu mentaati peraturan perundang-udangan terkait pembayaran pajak, jaminan kesehatan, keselamatan kerja dan ketenaga kerjaan (responsibilitas).

\section{KESIMPULAN}

Hasil penelitian menunjukan bahwa semakin baik implementasi human capital yang dilakukan oleh perusahaan makak inerja karyawan akan semakin meningkat. Semakin baik internalisasi corporate value yang dilakukan oleh karyawan makakinerja karyawan akan semakin meningkat atau karyawan yang mampu menginternalisasi dan mengaplikasikan nilai-nilai perusahaan, sehingga kinerja karyawan akan semakin baik. GCG tidak mempunyai pengaruh nyata terhadap kinerja karyawan. Kinerja karyawan mempunyai pengaruh nyata terhadap kinerja perusahaan. Implementasi prinsip-prinsip GCG mempunyai pengaruh nyata terhadap kinerja perusahaan.

\section{DAFTAR PUSTAKA}

Anis, I. 2013. Corporate Governance-Driven to Intellectual Capitaland Corporate Performance (Empirical Study in Indonesian Banking Industry). International Conference on Business, Economics, and Accounting. Bangkok, Thailand.

Astuti, P.D. 2011. Trust dan Kultur Organisasi Sebagai Penggerak Intellectual Capital terhadap Kinerja Organisasi. Jurnal Siasat Bisnis, 15(2): 267-283.

Atmadja, S.S. 2009. Making The Giant Leap, How to Unleash the Extraordinary Human Potential. Jakarta (ID). PT Gramedia Pustaka Utama.

Awan, M.A.S dan N. Sarfraz. 2013. The Impact of Human Capital on Company Performance and the Mediating Effect of Employee's Satisfaction.IOSR Journal of Business and Management.8(2):76-82.

Barrett. 2010. Cultural Capital A fundamental driver of financial performance. [internet]. [diunduh
2014, Maret 26]. Tersedia pada http : www.valuescentre.com

Chin, W.W. 1998."The Partial Least Squares Approach for Structural Equation Modeling", In Marcoulides, G.A. (Ed), Modern Method for Business Resaearch, Mahwah. NJ. Erlbaum Associates, hal. 295- 358.

Kaplan, R.S dan D.P. Norton. 1996. The Balanced Scorecard: Translating Strategy into Action. Massachusetts. Harvard Business School Press [UK].

Kessler, R. 2011. Competency Based Performance Reviews, Evaluasi Kinerja Karyawan untuk Mencapai Sasaran Strategis Organisasi. Verawaty Pakpahan, Penerjemah. Jakarta. PPM Manajemen. Terjemahan dari: Competency Based Performance Reviews, How to Perform Employee Evaluation the Fortune 500 Way.

[Kemen BUMN] Kementrian Badan Usaha Milik Negara. 2002. Keputusan Menteri Badan Usaha Milik Negara Nomor : KEP-117/MMBU/2002 tentang Penerapan Praktek Good Corporate Governance pada Badan Usaha Milik Negara (BUMN). Jakarta (ID). Kemen BUMN.

[KNKG] Komite Nasional Kebijakan Governance. 2006. Pedoman Umum Good Corporate Governance. Jakarta (ID). KNKG.

Mangkunegara, A.P. 2005. Manajemen Sumber Daya Manusia. Yogyakarta (ID). PT. Remaja Rosda Karya.

Mayo, A. 2000. The Role of Employee Development in The Growth of Intellectual Capital, Personal Review. 29 (4).

Ployhart, R.E. dan T.P. Moliterno. 2011. Emergence of the Human Capital Resource: A Multilevel Model. Academy of Management Review, 36: 127-150.

[PTPN VII] PT Perkebunan Nusantara VII. 2013. Laporan Tahunan (Anual Report) PT Perkebunan Nusantara VII. Bandar Lampung (ID): PTPNVII.

Purwanto, B. 2010. Manajemen SDM Berbasis Proses. Jakarta (ID). Grasindo.

Sharabati, A.A., S.N. Jawad dan Bontis. 2010. Intellectual Capital and Business Performance in the Pharmaceutical Sector of JORDAN. Journal Management Decision. (48)1: 105-131.

Suryadi, A. dan H. Rosyidi 2013. Kinerja Karyawan Ditinjau dari Analisis Faktor Budaya Perusahaan. Jurnal Penelitian Psikologi. 04(2): 166-180. 
Uddin, M.J., R.H. Luva, S.M. Hossian. 2013. Impact of Organizational Culture on Employee Performance and Productivity. International Journal of Business and Management. 8(2).

Wright, C., Moliterno. 2013. Strategic Human Capital: Crossing the Great Divide. Journal of Management. 20(10):1-18 doi: 10.1177/0149206313518437.
Wu, M.F, Y.J. Lee and G.L. Wang. 2012. To Verify How Intellectual Capital Affects Organizational Performance in Listed Taiwan IC Design Companies with Considering the moderator of Corporate Governance. The Journal of Global Business 8(1). 